\title{
VIABILIDADE ECONÔMICA DO GÁS OZÔNIO COMO FUMIGANTE EM GRÃOS DE MILHO ARMAZENADOS ${ }^{1}$
}

\author{
Alexandre de Melo Pereira², Lêda Rita D’Antonino Faroni ${ }^{3}$, Aziz Galvão da Silva Júnior ${ }^{4}$, \\ Adalberto Hipólito de Sousa ${ }^{5}$, Juliana Lobo Paes ${ }^{6}$
}

\begin{abstract}
RESUMO
Este trabalho teve por objetivo estudar a viabilidade econômica da utilização do ozônio como fumigante. Adotou-se, como parâmetro de produção, a diferença do valor final da massa específica aparente dos grãos ozonizados com os não-ozonizados, em diferentes temperaturas da massa de grãos (20, 30, 35 e $40 \stackrel{\circ}{\circ}$ ), armazenados à temperatura ambiente durante 180 dias. Os indicadores usados na análise econômica foram o tempo de retorno do capital, o valor presente líquido e a taxa interna de retorno, utilizando uma taxa de desconto de $6 \%$ ao ano. Os indicadores demonstraram maior rentabilidade de aplicação do ozônio, quando os grãos de milho foram armazenados durante 90, 135 e 180 dias após a ozonização, realizada na temperatura da massa de grãos a $20{ }^{\circ} \mathrm{C}$.
\end{abstract}

Palavras-chave: ozonização, proteção de grãos, análise econômica.

\section{ABSTRACT \\ Economical Viability of Ozone use as Fumigant of Stored Corn Grains}

This study was done to determine the economical viability of using ozone to fumigate stored corn. The difference between the apparent specific-grain-mass of ozone-treated and non-treat grains was used as production parameter for corn stored for 180 days at $20,30,35$ or $40{ }^{\circ} \mathrm{C}$. The indicators used for economical analysis were time period for capital return, present net value and inner return rate using a discount rate of $6 \%$ per year. The indicators showed higher profit with ozone application for grains stored for 90,135 and 180 days at $20^{\circ} \mathrm{C}$.

Keywords: ozonization, grain protection, economical analysis.

\footnotetext{
Recebido para publicação em 04.09.2006

${ }^{1}$ Parte da Tese de Mestrado do primeiro autor com recursos CNPq.

${ }^{2}$ Mestre em Engenharia Agrícola, Departamento de Engenharia Agrícola - DEA/UFV, Viçosa, MG, 36570-000.

${ }^{3}$ Professora Adjunta - DEA/UFV, Viçosa, MG, 36570-000. E-mail: lfaroni@ufv.br

${ }^{4}$ Professor Adjunto do Departamento de Economia Rural - DER/UFV, Viçosa - MG, 36570-000.

${ }^{5}$ Mestrando em Entomologia, Departamento de Biologia Animal - DBA/UFV, Viçosa - MG, 36570-000.

${ }^{6}$ Mestranda em Engenharia Agrícola - DEA/UFV, Viçosa - MG, 36570-000.
} 


\section{INTRODUÇÃO}

A agroindústria brasileira vem se destacando com o aumento da produção, principalmente de grãos, obtido mediante investimentos em novas tecnologias de plantio e colheita, além do uso de variedades mais produtivas, o que tem tornado o País um dos maiores produtores de grãos no mundo. A produção brasileira de milho é responsável, atualmente, por $33,5 \%$ da produção total de grãos do país, cerca de 122,7 milhões toneladas, segundo a estimativa da safra de 2005/2006 (CONAB, 2006).

A conservação de grãos e sua proteção durante 0 armazenamento constituem uma necessidade social e econômica. Toda reserva destinada à alimentação deve ser cuidadosamente conservada durante 0 armazenamento, para que o seu valor nutritivo não se altere. O tipo de grão e o tratamento a que este foi submetido durante seu manejo e processamento irão orientar a definição do procedimento correto a ser adotado em seu armazenamento. No entanto, o Brasil não possui um sistema eficiente para armazenagem de grãos e investe pouco em novas tecnologias póscolheita, convivendo com elevadas perdas causadas por insetos-praga que infestam grãos e subprodutos armazenados.

Atualmente, o setor agrícola enfrenta o problema do baixo valor agregado de seus produtos e do alto custo de seus insumos, que podem reduzir a margem de lucro da atividade do setor agrícola (SANTOS, 2002). Em razão dos resultados de pesquisas que apontam o potencial do ozônio no controle de fungos e insetos-praga de grãos armazenados, este gás tem se tornado uma importante alternativa para proteção de produtos armazenados. Sua utilização na agricultura vem se tornando atraente, pois, pode ser gerado no próprio local de uso, além de descartar a necessidade de embalagens e transporte de mercadorias (MENDEZ et al., 2003).

Kells et al. (2001), avaliando a eficácia do ozônio como fumigante para desinfestação de milho armazenado, verificaram que o tratamento de 8,9 toneladas de grãos de milho com 50 ppm de ozônio, durante três dias, resultou uma faixa de mortalidade entre 92 e $100 \%$ de adultos de $T$. castaneum e S. zeamais, de larva de Plodia interpunctella (HUBNER, 1813), tendo reduzido em $63 \%$ o nível de contaminação do fungo Aspergillus parasiticus. Os autores mencionam que Erdman (1980) observou a mortalidade de larvas de $T$. castaneum e $T$. confusum, ao serem expostas ao gás ozônio à concentração de 45 ppm.

Com relação à qualidade dos grãos, Strait (1998) constatou que o milho tratado com ozônio, na concentração de 50 ppm, não sofreu alteração na germinação. Mendez et al. (2003) observaram que não houve alterações na concentração de aminoácidos e ácidos graxos de grãos de trigo, milho, soja, arroz e milho-pipoca tratados com ozônio, na concentração de 50 ppm.

Diante destes resultados, verifica-se a necessidade de estudos detalhados sobre a viabilidade econômica desta nova tecnologia. Uma análise dessa natureza é de fundamental importância, pois traz contribuições ao setor agrícola, podendo auxiliar na tomada de decisão sobre o planejamento, administração e o retorno financeiro da atividade de armazenagem. Dessa forma, o presente trabalho foi desenvolvido com o propósito de estudar a viabilidade econômica da utilização de ozônio como fumigante.

\section{MATERIAL E MÉTODOS}

Os experimentos foram realizados no Setor de Pré-Processamento e Armazenamento de Produtos Agrícolas do Departamento de Engenharia Agrícola da Universidade Federal de Viçosa (UFV). Avaliou-se a viabilidade econômica do gás ozônio fumigado na dose de $50 \mathrm{ppm}$, durante 168 horas, aplicado em diferentes temperaturas da massa de grãos de milho $\left(20,30,35\right.$ e $\left.40^{\circ} \mathrm{C}\right)$. Para comparação dos resultados, ar ambiente foi aplicado durante 168 horas na massa de grãos de milho, nas mesmas condições do tratamento com gás ozônio. Na avaliação econômica foi utilizado - custo de implantação e utilização do equipamento, a massa específica aparente e os indicadores tempo de retorno do capital, valor presente líquido e taxa interna de retorno. 
O gás ozônio foi obtido de um gerador, desenvolvido pelo Departamento de Física do Instituto Tecnológico de Aeronáutica (ITA). No processo de geração do gás, utilizou-se como insumo ar ambiente seco (ponto de orvalho menor que $-40{ }^{\circ} \mathrm{C}$ ), passando através de um reator refrigerado, onde existe a Descarga por Barreira Dielétrica (DBD). Este tipo de descarga é produzido ao se aplicar uma alta tensão elétrica entre dois eletrodos paralelos, tendo entre eles um dielétrico (vidro) e um espaço livre, por onde flui o ar seco ou o oxigênio. Neste espaço livre é produzida uma descarga em forma de filamentos, onde são gerados elétrons com energia suficiente para produzir a quebra das moléculas de oxigênio, formando o ozônio $\left(\mathrm{O}_{3}\right)$.

O ar seco, utilizado como insumo, foi obtido a partir de um compressor de ar, instalado juntamente com um filtro de alumina. Na saída do filtro também foi instalada uma conexão com duas saídas: uma passando pelo gerador de ozônio e a outra indo diretamente para o sistema que utilizou ar ambiente (testemunha). A produção de ozônio foi regulada em função da tensão aplicada, ajustada no regulador de tensão do gerador e do fluxo de ar seco, monitorado com auxílio de um medidor de fluxo de ar. A concentração de ozônio foi medida por meio de um espectrofotômetro com precisão de $0,1 \mathrm{~g} \mathrm{~m}^{-3}$. Com o intuito de aumentar a resolução nas leituras de concentração, um multímetro foi conectado ao espectrofotômetro, a fim de possibilitar uma relação entre os valores lidos no espectrofotômetro $\left(\mathrm{g} \mathrm{m}^{-3}\right)$ e a corrente elétrica $(m A)$.

Para aplicação do ozônio e do ar ambiente, grãos de milho do tipo 1 (25 kg), classificados conforme a Portaria $n^{\circ} 845$, de 8.11.1976, do Ministério da Agricultura, foram acondicionados em seis recipientes cilíndricos de PVC com 20 $\mathrm{cm}$ de diâmetro e $100 \mathrm{~cm}$ de altura. Nas tampas inferior e superior dos cilindros, foram instaladas conexões para injeção e exaustão do gás. A 10 $\mathrm{cm}$ do fundo do recipiente, colocou-se uma tela metálica para sustentação dos grãos e formação de uma câmara, para melhor distribuição do gás. Os grãos de milho foram expostos ao ozônio e ao ar ambiente durante 168 horas.

Os cilindros, contendo os grãos de milho, foram acondicionados em câmaras climáticas com a temperatura do ar controlada conforme a temperatura da massa de grãos, que foi monitorada por meio de um sistema computacional de aquisição e armazenamento de dados, denominado 1-wire ${ }^{T M}$. Este sistema é constituído de uma rede de transmissão de dados, em que, através de um programa, um único cabo condutor permite a comunicação entre 0 computador $e$ os sensores de temperatura na massa de grãos (MARTINS et al., 2004).

Após exposição ao ozônio e ao ar atmosférico em cada temperatura, a massa de grãos foi homogeneizada e distribuída em frascos de vidro de 2,5 L, os quais foram armazenados em condições ambientes durante 180 dias. Para quantificar as perdas dos grãos de milho durante o armazenamento, foram feitas análises de massa específica aparente, segundo Brasil (1992), após o tratamento com ar e ozônio, a cada 45 dias.

A determinação da massa específica foi feita com auxílio da balança hectolítrica, com capacidade para $250 \mathrm{ml}$ ou um quarto de litro. Foram feitas cinco leituras para cada amostra, sendo escolhidas as três mais próximas. Como o peso hectolítrico de uma amostra varia de acordo com seu teor de umidade, fizeram-se determinações simultaneamente (BRASIL, 1992). Com base nos resultados de massa específica, foi calculado o custo da utilização do ozônio, comparando-se as possíveis perdas dos grãos tratados com o ozônio com aquelas dos nãotratados com este gás, armazenados durante seis meses.

Inicialmente, realizou-se um estudo das diferentes estruturas de custos, os quais foram divididos em custos fixos e custos variáveis. Como custos fixos foram estabelecidos aqueles que não dependem do nível de produção da unidade, como o custo de oportunidade do capital e a depreciação do gerador de ozônio. Os custos variáveis foram aqueles que dependeram diretamente do nível de produção da unidade, como os custos da matéria-prima para geração de ozônio, ou seja, o custo da energia elétrica (BUARQUE, 1991).

$\mathrm{Na}$ análise de custos (Quadro 1), foram considerados os valores de massa específica aparente dos grãos ozonizados e nãoozonizados, obtidos durante 180 dias de armazenamento, em que os valores de massa específica aparente, referentes a cada tratamento, foram adimensionalizados, convertendo a massa específica em massa específica relativa e dividindo-se os valores de massa específica por seu valor inicial. 
Os cálculos foram baseados no preço de $R \$$ 17,30, que corresponde à saca de $60 \mathrm{~kg}$ de milho, segundo a cotação da Bolsa Brasileira de Mercadorias, conforme demonstrativo do Quadro 1 para a temperatura de $20^{\circ} \mathrm{C}$.

Os custos relacionados nesta avaliação correspondem à implantação da nova tecnologia e ao processo de produção, em que foram considerados, como custo de implantação, o investimento feito para aquisição do equipamento gerador de ozônio, juntamente com o custo de oportunidade e a depreciação. Entretanto, os custos correspondentes ao processo de produção foram, basicamente, os custos de degradação do produto armazenado, tratado com ozônio e não-tratado e o custo da energia elétrica para produção de ozônio. O custo da degradação do produto armazenado (Quadro 2) foi calculado com base nos valores de massa específica aparente, transformada em um adimensional e no preço de mercado da saca de milho, conforme apresentado no Quadro 1.

Foram calculados os custos do consumo da energia elétrica, utilizada para geração do ozônio, considerando-se uma situação hipotética para aplicação de ozônio em um silo de volume de $5.000 \mathrm{~m}^{3}$. De acordo com o fabricante, em função das características do gerador de ozônio e da concentração utilizada (50 ppm), o período de ozonização é de 13 dias. Sabendo-se que o consumo de energia, nesse período, seria de $576,58 \mathrm{kWh}$ e que o valor convencional do $\mathrm{kWh}$ para o consumidor rural equivale a $R \$ 0,30$ (CEMIG, 2006), calculou-se o custo da energia elétrica por quilograma de grãos de milho, conforme Quadro 2.

O custo da energia para controlar a temperatura da massa de grãos não foi considerado na análise econômica, pois o objetivo do controle da temperatura foi apenas simular as possíveis condições ambientais em que se pode armazenar grãos no Brasil.

Juros e custo de oportunidade (equação 1) pode ser definido como a remuneração acrescida pelo direito de uso de uma unidade monetária por um período de tempo. O custo de oportunidade do capital é dado pela sua taxa de crescimento no tempo em seu melhor uso alternativo, independentemente de 0 custo de oportunidade do capital ser próprio ou de terceiros (NORONHA, 1987). A taxa de juros utilizada para análise econômica foi de $1 \%$ ao mês, a mesma paga pelo investimento feito em caderneta de poupança. O Quadro 3 demonstra 0 procedimento do cálculo dos juros e custo de oportunidade para a temperatura de 20 ${ }^{\circ} \mathrm{C}$ em cada período de armazenamento.

$$
F=P(1+J)^{n}
$$

em que

$\mathrm{F}=$ valor acrescido de juros (remuneração

paga);

$\mathrm{P}=$ valor investido;

$\mathrm{J}=$ juros;

$\mathrm{n}=$ período em tempo.

Depreciação (equação 2) é uma reserva contábil destinada a gerar fundos necessários para a substituição do capital investido em bens produtivos de longa duração. É a maneira que a empresa dispõe de recuperar bens de capital, ficando em condições de repô-los quando não mais for economicamente útil (NORONHA, 1987). Em um fluxo de caixa a depreciação é considerada como entrada ou receita, pois não é um custo desembolsado. Para o cálculo de depreciação, por ser um bem considerado durável, a taxa de depreciação utilizada no gerador de ozônio foi de $10 \%$ ao ano, sendo posteriormente calculada para cada período de armazenamento e quilograma do produto, como se vê na equação:

$$
D t=\frac{B-F}{N}
$$

em que

$\mathrm{Dt}=$ valor da depreciação em qualquer ano,

$\mathrm{R} \$$;

$\mathrm{B}=$ valor depreciável durante os anos de vida útil do ativo, $\mathrm{R} \$$;

$\mathrm{F}=$ valor final, $\mathrm{R} \$$; $\mathrm{e}$

$\mathrm{N}=$ vida útil, ano.

No quadro 4 é demonstrado o procedimento do cálculo da depreciação para a temperatura de $20{ }^{\circ} \mathrm{C}$ em cada período de armazenamento. 
As receitas são os fluxos de recursos financeiros que a implantação da tecnologia recebe ao longo de sua vida útil, direta ou indiretamente, conforme suas operações (BUARQUE, 1991). A receita foi calculada utilizando o valor da degradação ocorrida na massa específica aparente ao longo do armazenamento (Quadro 2), descontando-se os custos de depreciação, de oportunidade e os da energia elétrica dos valores monetários dos grãos ozonizados. Posteriormente, foram subtraídos os valores monetários da massa específica aparente dos grãos tratados com ozônio em relação aos não-tratados, obtendo os resultados do lucro (Quadro 5).

Tendo como base os dados de renda (custos e receitas), estabeleceram-se: o tempo de retorno de capital (TRC), o valor presente líquido (VPL) e a taxa interna de retorno (TIR) para os períodos de armazenamento em que a utilização do ozônio foi rentável em relação ao ar atmosférico, conforme cada temperatura da massa de grãos em que foram feitas as aplicações de ar e ozônio.

O tempo de retorno do capital (equação 3) consiste no tempo de funcionamento necessário para que se possa recuperar o capital investido. Por isso, é conhecido também como tempo de recuperação do capital (BUARQUE, 1991), sendo representado por:

$\sum_{t=0}^{n} L t=0$

em que

$\mathrm{L}=$ fluxo líquido do projeto, $\mathrm{R} \$$;

$\mathrm{t}=$ tempo, ano;

$\mathrm{N}=$ horizonte do projeto, ano; $\mathrm{e}$

$t=0,1,2, \ldots, N$ sendo $N \geq n$

Em geral, $\mathrm{L} 0<0$ e $\mathrm{Lt}>0$ para $\mathrm{t} \geq 1$.

O valor presente líquido VPL (equação 4) representa 0 retorno líquido gerado pelo investimento. Foi calculado de acordo com os fluxos monetários (receitas e custos), medindo-se as diferenças entre as receitas operacionais líquidas e os investimentos adicionais feitos com o projeto (WOILER, 1986).

$V P L=\sum_{t=0}^{N} \frac{L t}{(1+\rho)^{t}}$ em que

$\mathrm{VPL}=$ valor presente, $\mathrm{R} \$$;

$\mathrm{N}=$ horizonte do projeto, ano;

$\mathrm{L}=$ fluxo líquido do projeto, $\mathrm{R} \$$;

$\mathrm{t}$ = tempo, ano; $\mathrm{e}$

$\rho=$ taxa de desconto relevante para a empresa.

A taxa interna de retorno (equação 5) é o valor de " $\rho$ " que torna o valor presente do fluxo líquido igual a zero:

$0=\sum_{t=0}^{N} \frac{L t}{(1+\rho)^{t}}$

em que

$\mathrm{N}=$ horizonte de projeto, ano;

$\mathrm{L}=$ fluxo líquido do projeto, $\mathrm{R} \$$;

$\mathrm{t}=$ tempo, ano; $\mathrm{e}$

$\rho=$ taxa interna de retorno (a ser calculada).

\section{RESULTADOS E DISCUSSÃO}

Observa-se, na Figura 1, que a fumigação com ozônio sobre grãos de milho apresentou retorno de capital quando foram utilizadas as temperaturas da massa de grãos a 20, 30 e 35 ${ }^{\circ} \mathrm{C}$ no momento da ozonização. Na temperatura de $20{ }^{\circ} \mathrm{C}$, a fumigação foi rentável a partir de 90 dias de armazenamento, num horizonte de quatro anos. Essa rentabilidade foi maior e teve retorno mais rápido nos períodos de armazenamento subseqüentes, em que se constatou que a melhor rentabilidade e o mais rápido retorno do investimento ocorreram quando o armazenamento dos grãos foi feito no período de 180 dias depois da aplicação do ozônio, no horizonte de um ano. Quando a ozonização foi feita com a temperatura da massa de grãos a 30 C, só foi constatado retorno de capital quando os grãos foram armazenados durante 180 dias, num horizonte maior que cinco anos. Para os grãos ozonizados na temperatura de $35{ }^{\circ} \mathrm{C}$ só foi observado retorno de capital quando os grãos de milho foram armazenados durante 90 e 135 dias, em que o menor horizonte para que a tecnologia se torne viável corresponde ao planejamento de utilização do ozônio durante dois anos, caso o armazenamento seja feito por um período mínimo de 135 dias após a ozonização. Já na temperatura de $40{ }^{\circ} \mathrm{C}$ não foi observado retorno de capital até 180 dias de armazenamento, no horizonte de dez anos. 
A viabilidade econômica da utilização de ozônio pelo método do valor presente líquido (VPL) é indicada pela diferença positiva entre receitas e custos, atualizados de acordo com a taxa de descontos de $6 \%$ ao ano, conforme Tsukamoto Filho et al. (2003). Observa-se, na Figura 2, que o VPL foi maior que zero na temperatura de $20{ }^{\circ} \mathrm{C}$ em todos os períodos de armazenamento dos grãos que tiveram receita (90, 135 e 180 dias), em que se constatou que o VPL aumentou proporcionalmente com o período de armazenamento. Quando a ozonização dos grãos foi feita na temperatura de $30^{\circ} \mathrm{C}$, o VPL foi maior que zero apenas no período de armazenamento de 180 dias. Na temperatura de $35^{\circ} \mathrm{C}$, o VPL foi maior que zero nos períodos de armazenamento de 90 e 135 dias, sendo esse valor maior quando os grãos foram armazenados durante 90 dias. Já na temperatura de $40^{\circ} \mathrm{C}$, os valores de VPL de todos os períodos de armazenamento que tiveram receitas foram menores que zero.

$\mathrm{Na}$ análise de implantação de uma tecnologia, independentemente das alternativas de investimento, o critério de decisão consiste em aceitá-lo se VPL $\geq 0$ (NORONHA, 1987). Tsukamoto Filho et al. (2003) afirmam que, dada a independência do investimento numa determinada tecnologia, as decisões de aceitação ou rejeição de um projeto são perfeitamente coincidentes com aquelas obtidas quando se aplica o método do VPL. Dessa forma, pode-se inferir que a fumigação com ozônio pode se tornar economicamente viável quando a ozonização for feita nas temperaturas da massa de grãos de 20,30 e $35{ }^{\circ} \mathrm{C}$, preferencialmente com os períodos de armazenamento em torno de 135 dias.

A taxa interna de retorno (TIR) de um projeto, também chamada de eficiência marginal do capital, é a taxa de desconto que iguala o valor atual das receitas futuras ao valor atual dos custos futuros do projeto, ou seja, é a taxa média de crescimento de um investimento (TSUKAMOTO FILHO et al., 2003). A TIR do presente investimento (Figura 3) aumentou proporcionalmente com 0 período de armazenamento quando a ozonização dos grãos foi feita na temperatura da massa de grãos de 20 ${ }^{\circ} \mathrm{C}$, em que as TIRs $14,33 \%$, 55,5\% e $76,6 \%$ correspondem, respectivamente, aos períodos de armazenamento de 90, 135 e 180 dias. $\mathrm{Na}$ temperatura de $30{ }^{\circ} \mathrm{C}$, a TIR foi maior que zero apenas no período de armazenamento de 180 dias, com percentual de $15,75 \%$. Para temperatura de $35{ }^{\circ} \mathrm{C}$, as TIRs correspondentes aos períodos de armazenamento de 90 e 135 dias foram, respectivamente, de 50 e $30 \%$. Já na temperatura de $40{ }^{\circ} \mathrm{C}$, todas as TIRs foram negativas, indicando a inviabilidade de utilização do ozônio nesta temperatura, confirmando, assim,os resultados observados para o retorno do capital e para o VPL.

Os valores das TIRs maiores que zero encontrados neste trabalho indicam que as receitas descontadas seriam superiores aos custos descontados, mesmo se o mercado trabalhasse com taxas superiores a 10\% ao ano.

Os resultados deste trabalho mostram estreita relação com a temperatura na qual se inicia a degradação do ozônio. Como o processo de degradação do ozônio principia-se entre temperaturas variando de 30 a $35{ }^{\circ} \mathrm{C}$ (DELIMPASIS, 2001), é muito provável que o comprometimento do retorno do capital na temperatura de $30 \stackrel{\circ}{ } \mathrm{C}$ esteja relacionado com perdas na concentração do ozônio, que podem ter comprometido a proteção dos grãos contra o ataque de insetos $e$, conseqüentemente, provocado perdas da massa específica aparente dos grãos. No caso da temperatura de $35 \stackrel{\circ}{\circ}$, atribuem-se os resultados positivos da análise econômica à ação conjunta do ozônio, mesmo em processo de degradação, com a temperatura da massa de grãos, pois esta temperatura é considerada desfavorável ao desempenho da atividade biológica da espécie de inseto $S$. zeamais (REES, 1996), considerado o principal inseto-praga de grãos de milho armazenados no Brasil.

O baixo desempenho econômico obtido na temperatura de $40{ }^{\circ} \mathrm{C}$ pode ser atribuído ao fato de temperaturas próximas a esta serem letais em poucas horas aos insetos-praga de produtos armazenados (BURKS et al., 2000), tendo como conseqüência a equivalência dos valores da massa específica dos grãos de milho tratados e não-tratados com o ozônio. Conseqüentemente, as receitas provenientes dos grãos tratados com ozônio e não-tratados tiveram valores próximos, portanto sem viabilidade econômica nesta temperatura. 


\section{CONCLUSÕES}

Os resultados permitiram as seguintes conclusões:

- Os indicadores financeiros demonstraram rentabilidade da fumigação do gás ozônio quando os grãos de milho foram armazenados durante 90, 135 e 180 dias após a ozonização realizada na temperatura da massa de grãos de $20^{\circ} \mathrm{C}$.

- Já na temperatura de $30^{\circ} \mathrm{C}$, constatou-se rentabilidade apenas no período de 180 dias de armazenamento após a ozonização.

- Na temperatura de $35^{\circ} \mathrm{C}$, os indicadores demonstraram rentabilidade de aplicação do ozônio quando os grãos foram armazenados nos períodos de 90 e 135 dias após a ozonização.

- Na temperatura de $40 \stackrel{\circ}{ } \mathrm{C}$, não foi observada rentabilidade da utilização do ozônio em nenhum dos períodos de armazenamento.

\section{AGRADECIMENTOS}

Este trabalho faz parte do Projeto Efeito da fumigação com ozônio na qualidade dos grãos de milho e sua viabilidade econômica, financiado pelo Conselho Nacional de Desenvolvimento Científico e Tecnológico CNPq e Instituto Tecnológico da Aeronaltica - ITA, a quem agradecemos.

\section{REFERÊNCIAS BIBLIOGRÁFICAS}

BRASIL. Regras para Análise de Sementes. Brasília: Ministério da Agricultura, 1992. 365p.

BUARQUE, C.; Avaliação econômica de projetos. In: BUARQUE, C. Avaliação Financeira e Econômica. Editora Campus, 1991 p.130-180.

BURKS, A.S.; JOHNSON, J.A; MAIER, D.E.; HEAPS, J.W. Temperature In: SUBRAMANYAM, B.; HAGSTRUM, D.W. Alternatives to pesticides in storedproduct IMP. Massachusetts: Kluwer Academic, 2000. p.73-104.
CEMIG - Cemig distribuição Tarifas de energia (Tarifa convencional). www.cemig.com.br/. 06 jan. 2006.

CONAB 2006 - Companhia nacional de abastecimento. Acompanhamento da safra 2005/2006 - 2o Levantamento novembro/ 2005. www.conab. gov.br/. 01 fev. 2006.

DELIMPASIS, K. Ozone application for wastewater color removal. Public Service Ads by Google, 2001. www.etelescope.gr/en/cat04/art04_010601.htm. 22 fev. 2006.

ERDMAN, H.E. Ozone toxicity during ontogeny of two species of flour beetles, Tribolium confusun e T. castaneum. Environmental Entomology, v. 9, p.16-17, 1980.

KELLS, S.A.; MASON, L.J.; MAIER, D.E.; WOLOSOSHUK, C.P. Efficacy and fumigation characteristics of ozone in stored maize. Journal of Stored Products Research, v. 37, p.371-383, 2001

MARTINS, J.H.; MONTEIRO, P.M.B.; MOTA, A.M.N.; FONSECA, J.A.G. The 1wire $^{T M}$ System - An Application for Agricultural Processes. In: Portuguese Conference on Automatic Control, 6, 2004, Faro, Portugal. Proceedings... Faro, Portugal: Controlo, 2004, v.2, p.602-607.

MENDEZ, F.; MAIER, D.E.; MASON, L.J.; WOLOSHUK, C.P. Penetration of ozone into columns of stored grains and effects on chemical composition and performance. Journal of Stored Products Research, v.39, p.33-44, 2003.

NORONHA, J.F. Projetos agropecuários: administração financeira, orçamento e viabilidade econômica. 2.ed. São Paulo: Atlas, 1987. 269p.

REES, D.P. Coleptera In: SUBRAMANYAM, B.; HAGSTRUM, D.W. Integrated managemente of insect in stored products. New York: Marcel Dekker, 1996. p.1-39. 
SANTOS, A.K.; FARONI, L.R.D.; GUEDES, R.N.C.; SANTOS, J.P.; ROZAZDO, A.F. Nível de dano econômico de Sitophilus zeamais (M.) em trigo armazenado. Revista Brasileira de Engenharia Agrícola e Ambiental, Campina Grande, v.6, n.2, p.273-279, 2002.

STRAIT, C.A. Efficacy of ozone to control insects and fungi in stored grain. West Lafayette: Purdue University, 1998, 59p. (Tese de Mestrado).
TSUKAMOTO FILHO, A.A.; SILVA, M.L.; COUTO L.; MULLER, M.D. Análise econômica de um plantio de teca a desbastes. Revista Árvore, v.27, n.4, p.487494, 2003.

WOILER, S.; MATHIAS, F. Projetos, planejamento, elaboração e análise. In: WOILER, S.; MATHIAS, F. Critérios quantitativos de análise econômica de projetos. Atlas, 1986. p.172-230.

\section{QUADROS E FIGURAS}

Quadro 1. Exemplo da conversão da massa específica em uma adimensional e o preço da saca de milho, segundo cotação da Bolsa Brasileira de Mercadorias, para tratamento com ozônio e ar atmosférico na temperatura da massa de grãos a $20 \stackrel{\circ}{ } \mathrm{C}$

\begin{tabular}{|c|c|c|c|c|c|c|c|c|}
\hline \multirow{2}{*}{$\begin{array}{c}\text { Período de } \\
\text { armazenamento } \\
\text { Dia }\end{array}$} & \multicolumn{2}{|c|}{$\begin{array}{l}\text { Massa específica } \\
\text { do milho }\end{array}$} & \multicolumn{2}{|c|}{ Quantidade (em kg) } & \multicolumn{2}{|c|}{$\begin{array}{l}\text { Quantidade de } \\
\text { milho }(\mathrm{t})\end{array}$} & \multicolumn{2}{|c|}{ Preço do Milho } \\
\hline & Ozônio & $\mathrm{Ar}$ & Ozônio & $\mathrm{Ar}$ & Ozônio & $\mathrm{Ar}$ & $\mathrm{R} \$ /$ Saca & $\mathrm{R} \$ / \mathrm{kg}$ \\
\hline 0 & 714,3 & 710,2 & 1 & 1 & 3571,5 & 3551 & 17,30 & 0,288333 \\
\hline 45 & 710,5 & 709,6 & 0,99468 & 0,99915517 & 3552,5 & 3548 & 17,30 & 0,288333 \\
\hline 90 & 706,6 & 694 & 0,98922 & 0,97718952 & 3533 & 3470 & 17,30 & 0,288333 \\
\hline 135 & 668,1 & 642 & 0,935321 & 0,90397071 & 3340,5 & 3210 & 17,30 & 0,288333 \\
\hline 180 & 595,6 & 561,8 & 0,833823 & 0,79104478 & 2978 & 2809 & 17,30 & 0,288333 \\
\hline
\end{tabular}

Quadro 2. Preço da degradação do milho e o custo da energia para ozonizar um volume de $5.000 \mathrm{~m}^{3}$

\begin{tabular}{|c|c|c|c|c|c|}
\hline \multirow{3}{*}{$\begin{array}{c}\text { Período de } \\
\text { armazenamento } \\
\text { (dia) }\end{array}$} & \multirow{2}{*}{\multicolumn{2}{|c|}{$\begin{array}{c}\text { Degradação } \\
\mathrm{R} \$ / \mathrm{kg}\end{array}$}} & \multirow{3}{*}{$\begin{array}{c}\text { Consumo de Energia } \\
\text { kW }\end{array}$} & \multirow{2}{*}{\multicolumn{2}{|c|}{$\begin{array}{c}\text { Custo da Energia } \\
R \$ 0,30 / \mathrm{kWh}\end{array}$}} \\
\hline & & & & & \\
\hline & Ozônio & $\mathrm{Ar}$ & & $\mathrm{R} \$ / \mathrm{kWh}$ & $\mathrm{R} \$ / \mathrm{kg}$ \\
\hline 0 & 0,288333 & 0,288333 & 147,84 & 576,58 & 0,000161 \\
\hline 45 & 0,286799 & 0,28809 & 147,84 & 576,58 & 0,000162 \\
\hline 90 & 0,285225 & 0,281756 & 147,84 & 576,58 & 0,000163 \\
\hline 135 & 0,269684 & 0,260645 & 147,84 & 576,58 & 0,000173 \\
\hline 180 & 0,240419 & 0,228085 & 147,84 & 576,58 & 0,000194 \\
\hline
\end{tabular}

*valor de corrente elétrica medida em amperes.

Quadro 3. Exemplo do cálculo do custo de oportunidade

\begin{tabular}{cccc}
\hline \multirow{2}{*}{$\begin{array}{c}\text { Período de } \\
\text { armazenamento }\end{array}$ (dia) } & Montante & \multicolumn{3}{c}{ Custo de Oportunidade } \\
\cline { 2 - 4 } & $\mathrm{R} \$$ & $\mathrm{R} \$$ & $\mathrm{R} \$ / \mathrm{kg}$ \\
\hline 0 & $15.000,00$ & 0,00 & 0,00 \\
45 & $15.225,00$ & 225,00 & 0,000063 \\
90 & $15.453,38$ & 453,37 & 0,000131 \\
135 & $15.685,18$ & 685,18 & 0,000213 \\
180 & $15.920,45$ & 920,45 & 0,000328 \\
\hline
\end{tabular}


Quadro 4. Demonstrativo da depreciação do gerador de ozônio ocorrida no período de seis meses para fumigação com ozônio na temperatura da massa de grãos de $20 \stackrel{\circ}{\circ}$

\begin{tabular}{ccccc}
\hline \multirow{2}{*}{$\begin{array}{c}\text { Período de } \\
\text { armazenamento }\end{array}$ (dia) } & $\begin{array}{c}\text { Gerador de } \\
\text { ozônio }(\mathrm{R} \$)\end{array}$ & \multicolumn{3}{c}{ Depreciação 10\% ao ano } \\
\cline { 2 - 5 } & & $\mathrm{R} \$ /$ ano & $\mathrm{R} \$ /$ período & $\mathrm{R} \$ / \mathrm{kg}$ \\
\hline 0 & $15.000,00$ & $1.500,00$ & 0,00 & 0,00 \\
45 & & $1.500,00$ & 187,50 & 0,000052780 \\
90 & & $1.500,00$ & 375,00 & 0,000106142 \\
135 & & $1.500,00$ & 562,50 & 0,000168388 \\
180 & & $1.500,00$ & 750,00 & 0,000251847 \\
\hline
\end{tabular}

Quadro 5. Demonstrativo do lucro da utilização do ozônio em função do período de armazenamento e da temperatura da massa de grãos

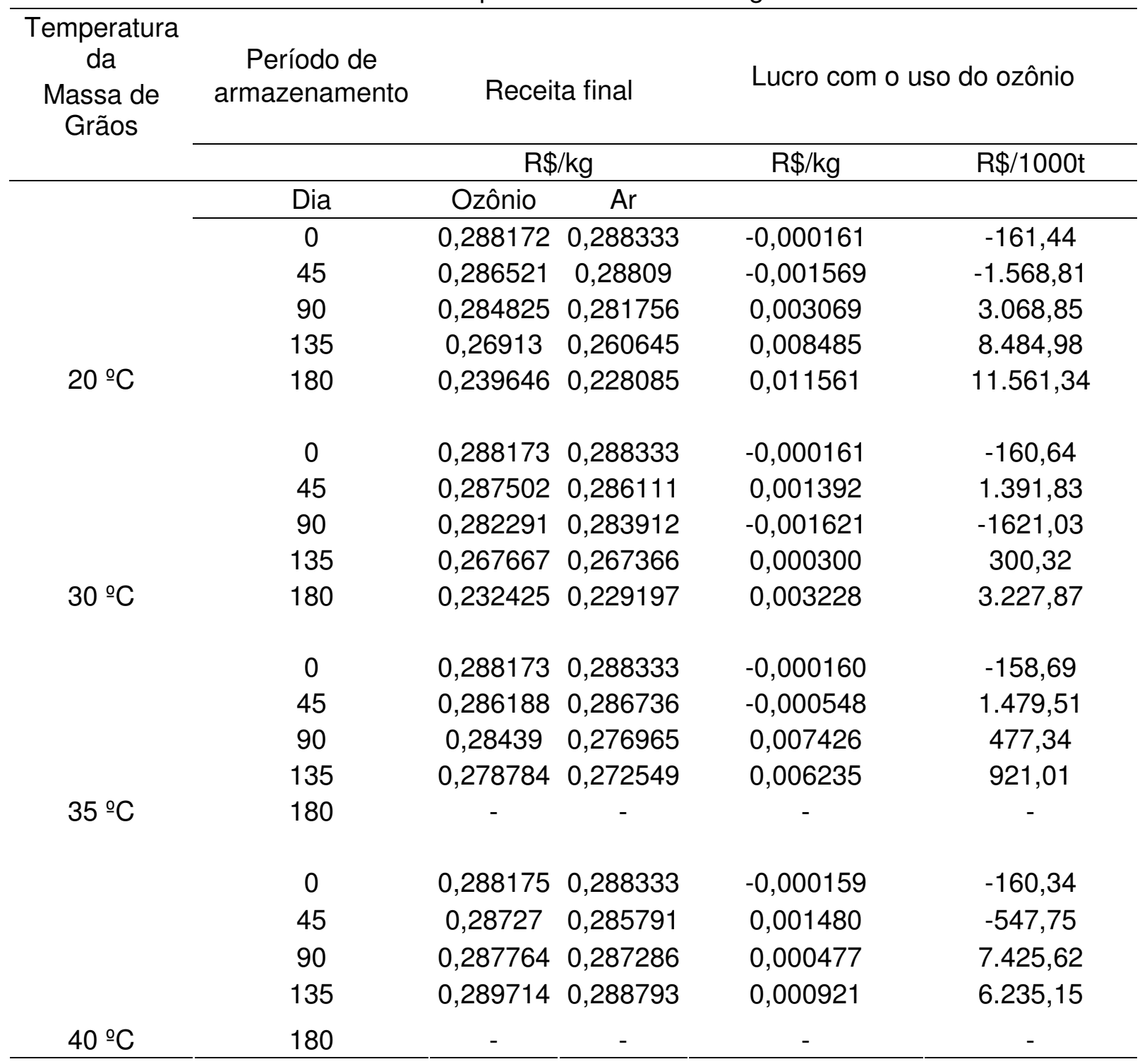


$\left(20^{\circ} \mathrm{C}\right)$

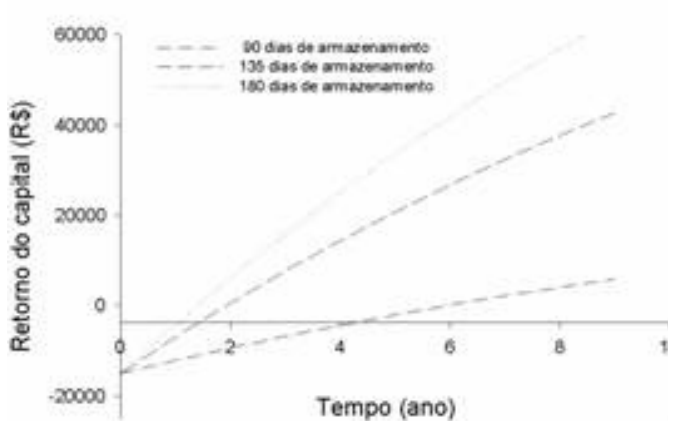

$\left(35^{\circ} \mathrm{C}\right)$

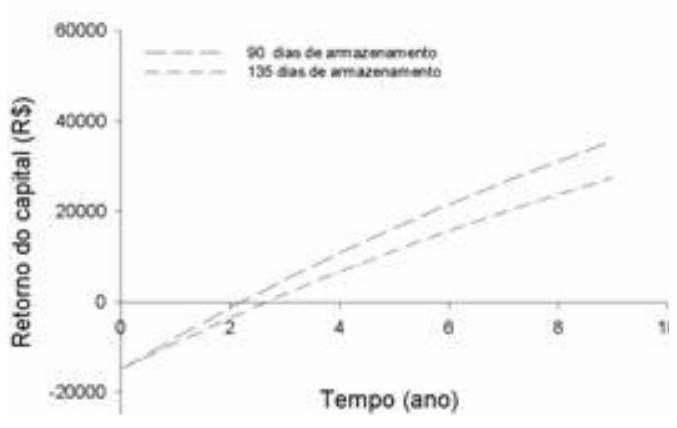

$\left(30^{\circ} \mathrm{C}\right)$

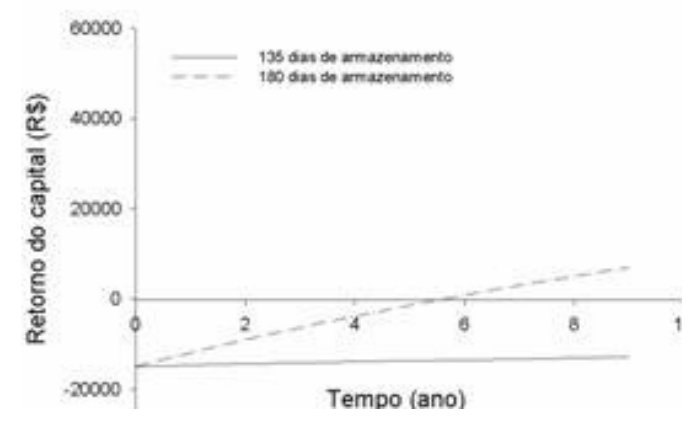

$\left(40^{\circ} \mathrm{C}\right)$

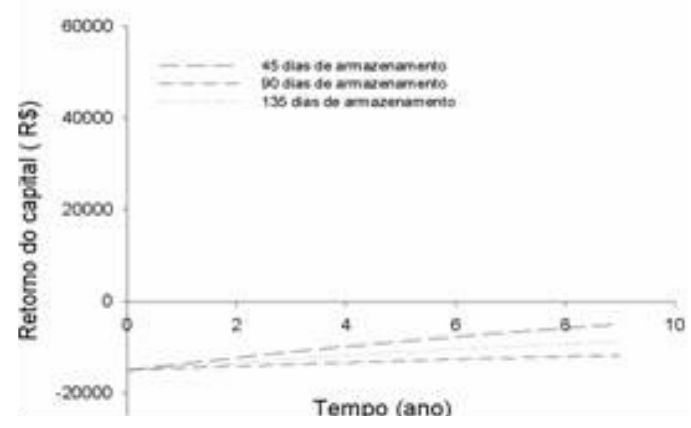

Figura 1. Efeito do período de armazenamento sobre o retorno do capital investido para aplicação do ozônio sobre os grãos de milho nas temperaturas de 20,30 , 35 e $40^{\circ} \mathrm{C}$

$\left(20^{\circ} \mathrm{C}\right)$

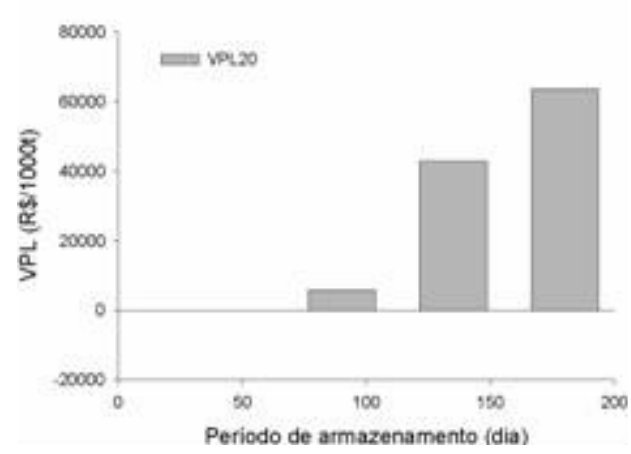

$(35 \times)$

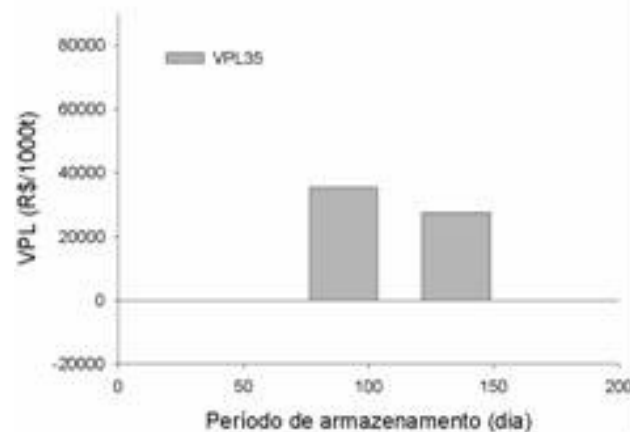

$\left(90^{\circ} \mathrm{C}\right)$

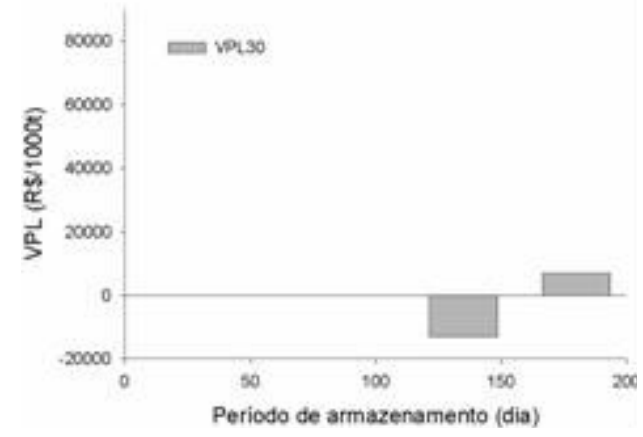

$\left(400^{\circ}\right)$

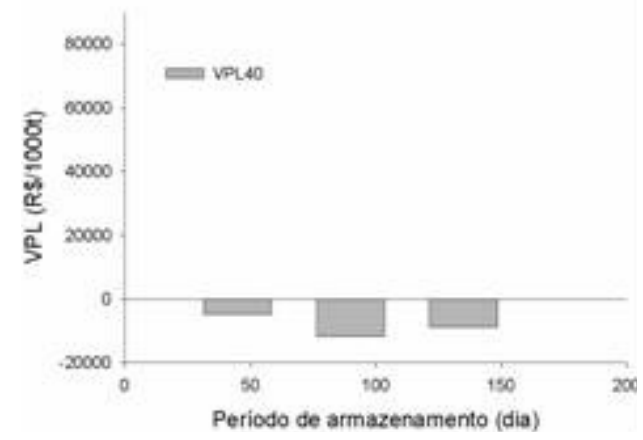

Figura 2. Efeito do período de armazenamento sobre o valor presente líquido para aplicação do ozônio sobre os grãos de milho nas temperaturas de 20, 30, 35 e $40 \stackrel{\circ}{ } \mathrm{C}$ 
$(20 \div)$

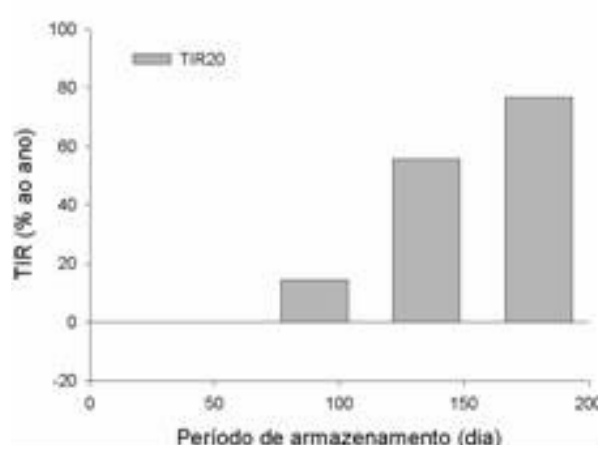

$\left(355^{\circ}\right)$

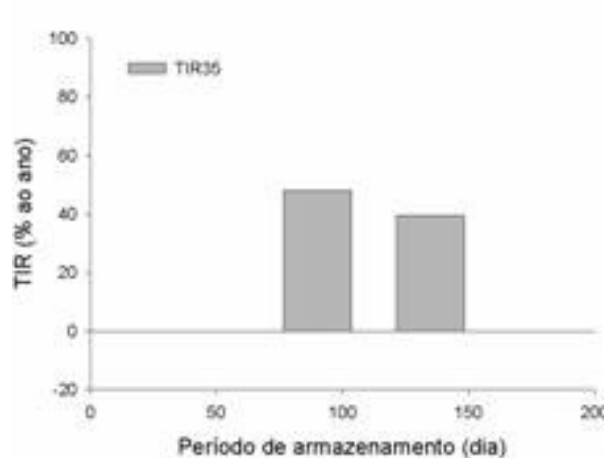

$(30,6)$

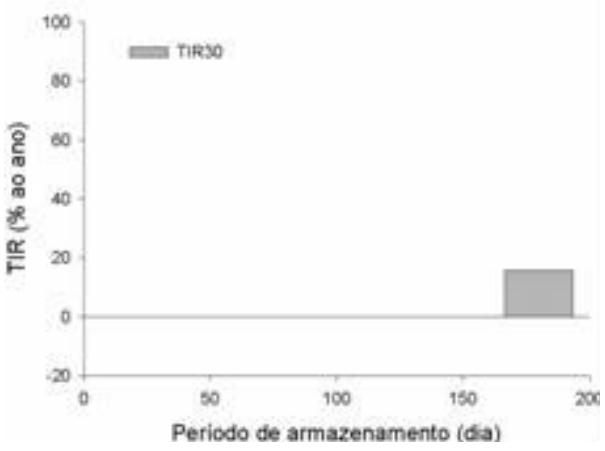

$\left(40^{\circ} \mathrm{C}\right)$

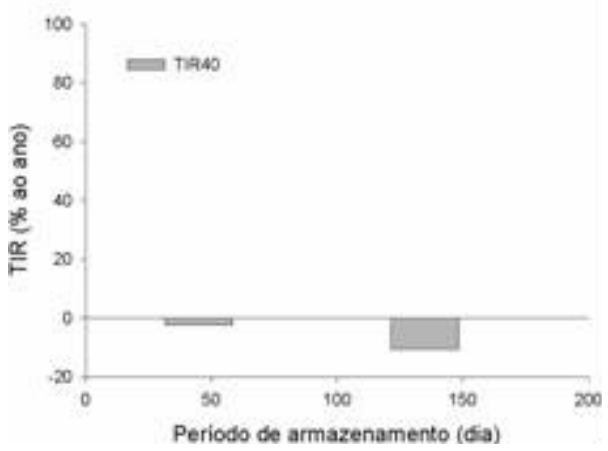

Figura 3. Efeito do período de armazenamento na taxa interna de retorno para aplicação do ozônio sobre os grãos de milho nas temperaturas de $20,30,35$ e $40 \stackrel{\circ}{C}$ 